IGUSABDER, 6 (2018): 607-619

\title{
Konus Kuronlarda Metal Primer ile Metal ve Plastik Sekonder Kuronlarda Tutunma Kuvvetinin in Vitro Olarak İncelenmesi
}

\author{
Özlem ERDEM POLAT*
}

\section{$\ddot{O} \mathbf{z}$}

Amaç: Periodontal problemi olan hastalarda konus kuronlu protez kullanımı oldukça yaygındır ve artmaktadır. Konus kuronlu protezler konusundaki çalışmalar çoğunlukla protezin yapım yöntemleri ve endikasyonu ile ilgilidir. Protezin kullanımına ait tutunma kuvveti kayıpları ile ilgili çalışmalar sınırlı sayıdadır. Çalışmada konus kuronlu protezlerde plastik esashı malzemelerden yapılmış sekonder kuronların kullanıma bağlı tutunma kayıpları üzerine çalışılmıştır. İn vitro deneylerde dört diş grubundan, üç değişik sekonder kuron malzemesi ile 10’ar adet örnek kullanılmıştır.

Yöntem: Cr-Ni alaşımdan $2^{\circ}$ 'lik açı ile primer kuronlar hazırlanmış ve üzerlerine $\mathrm{Cr}-\mathrm{Ni}$ alaşımı, Vectris ve Asetal-D malzemelerinden sekonder hazırlanmıştır. Caniklioğlu tarafından tasarlanan aygıt kullanılarak protezin takılıp çıkartılma işlemleri taklit edilmiştir. Kuronların ilk tutunma kuvvetleri ölçülmüş daha sonra 500, 1500 ve 3500 takıp çıkartma sonucundaki tutunma kuvveti değerleri tablolara not edilmiştir.

Bulgular: Bu çalışma bize 24 aylık protez kullanımı sonucunda meydana gelen tutunma kuvvetlerini ve kayıplarını karşılaştırma imkanı vermiştir.

Sonuç: En iyi tutunmanın metal sekonder kuronlarda olduğu, tutunma kayıplarında en düşük yüzde değerlerinin ise Vectris sekonder kuronlarda olduğu sonucuna varılmıştır.

Anahtar Sözcükler: Diş protezi, protez retansiyonu, asetal-dental, dental.

\footnotetext{
Özgün Araştırma Makalesi (Original Research Article)

Geliss / Received: 23.11.2018 \& Kabul / Accepted: 29.11.2018

* Dr. Öğr. Üyesi, İstanbul Gelişim Üniversitesi, Sağlık Hizmetleri Meslek Yüksekokulu, İstanbul, Türkiye, E-posta: oerdem@gelisim.edu.tr, ORCID ID https://orcid.org/oooo-0002-1459-3236
} 


\title{
In Vitro Evaluation of Retention in Conical Retained Dentures by Usage of Metal Primer with Metal and Plastic Resin Based Seconder Crowns
}

\begin{abstract}
Aim: Conical crown retained dentures has been widely and increasingly used especially in patients with periodontal problems. The studies about conical crown prosthesis are regarding indications and construction types of the prosthesis. The studies about the retention and loss of retention by usage are few. The aim of this study is to evaluate the changes in retention by usage of plastic resin based superstructures in conical crown retained dentures. In this in vitro study, 10 samples in each group are prepared for three different seconder crown material, in four different tooth groups.
\end{abstract}

Method: The primer crowns are prepared to have $2^{\circ}$ of angles are casted form $\mathrm{Cr}-\mathrm{Ni}$ alloy. The superstructures are also made of $\mathrm{Cr}-\mathrm{Ni}$ alloy, Acetal $\mathrm{D}$ and Vectris materials. The insertion and separation motion of the dentures were simulated by the experiment device which is specially designed by Caniklioğlu. The first retention forces in crowns were measured and then the values were noted after the insertion and separation procession of 500, 1500, 3500 times.

Findings: In this study, we achieve to compare the loss of retention forces in three different seconder crown materials in the usage of 24 months.

Conclusion: The results show that the seconder crowns made of metal have the best retention values and the least retention decrease per cent is shown by Vectris seconder material.

Keywords: Dental prosthesis, prosthesis retention, asetal-dental, dental.

\section{Giriş}

Diş hekimliğinde prostodonti, ağız içinde kaybolan fonksiyon, estetik ve sağlığın elde edilmesi için doğal dişlerin restorasyonu veya eksik dişlerin ve çevre dokularının yapay malzemelerle yenilenmesi işlemidir ${ }^{1}$.

Protetik tedavi uygulamalarını iki ana başlık altında toplamamız mümkündür²:

1- Sabit Protezler

2- Hareketli Protezler

a. Bölümlü Protezler

b. Tam Protezler 
Sabit protezler, ağız içinde bir veya daha fazla sayıda diş eksikliğinin olduğu durumlarda, çiğneme kuvvetlerinin destek dişler ve periodontal dokuları aracılığıyla çene kemiğine iletilmesini sağlayan ve hekim tarafından ağıza yerleştirildikten sonra hasta tarafından takıp çıkarılamayan protez türleridir³.

Hareketli protezler sınıfının bir alt grubu olan bölümlü protezler, çiğneme kuvvetlerini destek dişler ve periodontal dokularının yanı sıra alveol kreti ve mukoza aracılığıyla çene kemiğine ileten protetik tedavi uygulamaları olup hasta tarafından ağız hijyenini sağlamak amacıyla çıkarılıp takılabilen apareylerdir4.

Sabit-Bölümlü Protezler (Kombine Protezler) ise sabit ve hareketli bölümleri bir arada içeren protezler olup, çiğneme kuvvetlerinin mukoza ve periost aracılı̆̆ıyla çene kemiğine iletildiği ve sabit protezler gibi görev yapan ancak hasta tarafından çıkarılıp takılabilen protezler olduklarından hareketli protezler sınıfında değerlendirilebilirler. Kombine protezler şunları içeriri5,6:

a. Özel konstrüksiyonlu hassas çift bağlantı protezler,

b. Teleskop kuronlu protezler,

c. Konus kuronlu protezler

Araştırmalara göre, uzun süreli tam protez kullanımı durumunda alveol kemiği kayıplarınn kaçınılmaz olduğu ve ağızda doğal diş varlığının kemik yığılımını inhibe edici etkide olduğu ortaya koyulmaktadır7,8. Doğal diş destekli protetik tedavi türlerinde destek dişlerin periodontal algılamayı arttırması ve gelen okluzal kuvvetlerin destek dişler ve periost-alveol kemiği tarafından karşılanması ile kemik oluşumunu inhibe ettiği söylenmektedir ki her iki ana grubun özelliklerini taşıyan kombine protezler de aynı nedenlerle geniş bir kullanım alanına sahip olmaktadırlar9.

Konus ve teleskopik sistemli kombine protezler, iç kuron (primer, koping), dış kuron (sekonder kuron) ve protez kaidesinden oluşurlar ${ }^{10,11}$. Körber tarafından tanıtılan konus kuronlu teleskopik sistem, destek dişle kret arasında rijit bir bağlantıya sahiptir. Yapılacak tedavinin türü ve endikasyon şartlarına bağlı olarak teleskop ve konus sistemli kombine protezlerde altın primerle kaplanmış dişler üzerine, altın tam kuronlar, akrilik veneerlenmiş altın kuronlar veya kobalt-krom metal alt yapı üzerine kimyasal yolla veya ışınla sertleşen kompozit reçine veneerli kuronlar uygulanabilmektedirio,12. 


\section{Amaç}

Destek dişler ve çevre dokular üzerindeki olumlu etkileri, biyo-fizyo-mekanik avantajları ve estetik özellikleri nedeniyle günümüzde gittikçe artan bir kullanım alanına sahip olan konus sistemli kombine protez yöntemlerinde tutuculuğun miktarı ve zamanla gösterdiği değişim sıklıkla araştırmalara konu olmaktadır ${ }^{9,13}$.

Tam protez şeklinde uygulanan teleskop ve konus kuron sistemleri dışında diğer tüm sekonder yapım tekniklerinde metal primer kuron üzerine gelen üstyapı metal bazlıdır. $\mathrm{Bu}$ durumda sistemin tutuculuğu daima metalin metalle ilişkisi şeklindedir, ancak günümüzde estetik kaygılar ve diş hekimliğinde geliştirilen yeni metot ve malzemelere bağlı olarak farklı üstyapı malzemeleri kullanımı düşünülmektedir.

Sekonder kuron yapımında bu malzemelerin kullanıldığı firmalar tarafindan söylense de metal ve plastik kullanımı sonucu aşınmada farklılık olup olmayacağı konusunda yapılmış bir araştırma yoktur. Biz çalışmamızda metalle, yapay reçinelerin sekonder kuron malzemesi olarak kullanıldıklarında ne gibi değişiklikler ortaya çıkacağını incelemek üzere Asetal-D ve Vectris ve metalden yapılmış sekonder kuronlarda belli bir kullanım sonucunda ortaya çıkan tutunma kayıplarını belirlemeye çalıştık.

\section{Genel Bilgiler}

Teleskopik sistemlerin teknikte teleskop olarak bilinen uzak mesafe dürbünlerinde olduğu gibi birbiri içinde kayarak hareket etmeleri nedeniyle bu ismi aldıkları bildirilmektedir5. Teleskopik sistemler, destek dişe simante edilen iç kuron ve primer isimleriyle bilinen iç parça ve hareketli üst yapı ile rijit bir bağlantısı olan ve takılıp çıkarılabilen dış kuron ve sekonder olarak isimlendirilen üst yapı olmak üzere iki parçadan oluşmaktadır ${ }^{10,11}$.

Teleskop kuron sistemi perikuronal tutucu olmaları nedeniyle okluzal kuvvetleri destek dişlerin dikey eksenleri boyunca dağıtarak çok sayıda dişin splintlenmesini ve desteklenmesini sağlayan etkili bir çift kuron protezdir ${ }^{11,14}$.

Körber5 ${ }^{5} 1948$ yılından itibaren binin üzerinde kısmi dişsizlik vakasında uyguladığı silindirik teleskop kuronlarda kısa sürede önemli sonuçlar verebilecek değişiklikler olduğunu gözlemlemiştir. Silindirik teleskop kuronların uygulandığı çok sayıdaki vakada birbirlerine paralel olan yüzeylerde sürtünme sonucu aşınmalar meydana geldiğini ve bu durumun protezin tutuculuğunu önemli ölçüde azalttığını ya da 
yüzeylerin düzleşip birbirinden ayrılmaz hale gelerek protezin çıkartılmasının güçleştiğini ve bunun dokulara zarar verdiğini bildirmiştir. Bu amaçla yeni bir sistem geliştirmiş ve bu sisteme konus kuronlar(konik teleskop kuronlar) adını vermiştir. Konus kuronlar, teleskop kuron kavramının tek kuronların Taper açısı iyi belirlenmiş ve belirli bir eğim aralığıyla sınırlı tutulduğu, iç ve dış kuron arasındaki ara yüzde aktif tutuculuk yaratan varyasyonudur.

Konus kuronlarda tutuculuk sıkıştırma etkisine bağlıdır9. Silindirik teleskop kuronlarda bütün yan yüzler birbirine paralel iken konus kuronlarda sadece temas yüzeylerinde paralellik vardır. Konus kuronlar, alt ve üst tabanları farklı çaplarda bir kesik konidir ve tabandaki dairenin çapı her zaman tavandakinden büyüktür. Tam bir konide, yanal yüzlerin tepede kesiştiği yerde oluşan açı koniklik açısı (taper açısı) adını alır. Bu açının açıortayı üst yüzün ve alt tabanın merkezinden geçer. Koninin tabanında çapın bir ucundan açıortayına paralel olarak çizilen doğru koniklik açısının yarısına eşittir ve konverjans açısı adını alır. Konus kuronlarda elde edilen tutuculuk konus açısına bağlıdır. Konverjans açısı tutunma kuvvetini belirler. Değişik değerlerde olabilen açının saptanmasında "konometre" ismi verilen aygıt kullanılır. Körber konometre yardımıyla hem protez için en uygun giriş yolunun saptandığını hem de her diş için uygun konus açısının saptandığını belirtmektedir5,6,15. Koniklik açısı 2-8 ${ }^{\circ}$ arasında çeşitli değerlerde olabilir. Bu derecedeki artışın tutuculuk kuvvetini düşürdüğü, bu nedenle mümkün olan en küçük açının seçilmesi gerektiği bildirilmektedir. Körber'e göres, maksimum tutunma kuvvetine ulaşılabilmesi, sekonder kuronun iç yan yüzeyi ile primer kuronun dış yan yüzeyi arasında sıkı bir temasın sağlanabilmesine bağlıdır. Ancak konus kuronlarda "Aralık problemi” olarak tanımlanan ve primer kuronun okluzali ile sekonder kuronun okluzali arasında tek düzlemde ortaya çıkan boşluk bir problem yaratır. Kuronlar arasında bu aralığın oluşumunun başta gelen sebebi olarak sekonder kuronun döküm sonrası kontraksiyonu gösterilmektedir ki belli sınırlar dahilinde olması istenen bu aralık diş hekimliği rutin döküm yöntemleri edeniyle oluşmaktadır. Konus açısının büyük olduğu ve dökümde meydana gelen kontraksiyonun fazla olduğu durumlarda, sekonder kuron primer kuron üzerinde okluzal açıklık nedeniyle tam yerini alamayacak ve tutunma kuvveti azalacaktır.

Araştırmacılar koniklik açısındaki küçülmenin, özellikle $0^{\circ}$ ve $6^{\circ}$ lik primer kuronların söz konusu olduğu durumlarda, tutuculuk kuvvetini arttırdığını, koniklik açısında 
meydana gelen artışın tutuculuk kuvvetini düşürdüğünü bildirmektedirler. Konus kuronların uzun süreli kullanımı için açının $2^{\circ}$ 'den daha az olması tavsiye edilmektedir ${ }^{16}$.

Lenz ve ark. ${ }^{17}$ primer ve sekonderin 2000 kez takılıp çıkartılması sonrasında metal yüzeyindeki mikro düzensizliklerin azalması sonucu ayrılma kuvveti/uygulama kuvveti oranının \%30 azaldığını ve başlangıçtaki konus açısı değeri seçiminin önem kazandığını bildirmişlerdir ${ }^{18}$. Konus kuronlarda kullanılan üst yapı, iç kurona uygun olarak yapılır ve kuronun şeklini, konturunu ve okluzyonunu taklit eder. Primer kurona tam uyum içinde olan ve ağız içinde okluzyonu, konturu tamamlayacak olan sekonder kuron, tam metal kuron veya tam estetik kuron şeklinde olabileceği gibi, metal-akrilik veya metalseramik veneer kuron şeklinde de yapılabilir. Sekonder kuron yapımında kıymetli, yarı kıymetli, kıymetsiz metal alaşımları kullanılabilmektedir ${ }^{10}$.

Bazı araştırmacılar primer kuron için altın alaşımı kullanırken sekonder kuron için hem altın hem de kobalt-krom alaşımı kullanmış ve sekonder kuronları kimyasal yolla veya ışınla sertleşen kompozit reçinelerle veneerlemişlerdir ${ }^{19}$. Tüm bunların yanı sıra, son yıllarda gelişmekte olan teknolojiye paralel olarak diş hekimliğinde yer alan çeşitli yeni kuron malzemeleri de söz konusudur. Konumuzla ilgisi nedeniyle bu malzemelerin yapıları, kullanım alanları ve kullanım şekilleri ile ilgili ayrıntılı bilgi şu şekildedir.

\section{Asetal-D (Polioksimetilen-POM)}

Asetal-D tıbbın çeşitli dallarında Delrin adıyla tanınmakta olup mühendislik alanında da kullanılan kısmen kristal yapıda termoplastik bir malzemedir. Malzemenin esası polioksimetilen veya poliasetal olarak bilinen teknolojik polimerden oluşur ${ }^{20,21}$. Polioksimetilen geleneksel olarak, formaldehidin polimerizasyonundan elde edilir. Günümüzde en çok tercih edilen mühendislik termoplastikleri polikarbonat ve poliasetaldir3,22. Poliasetal, dayanıklılık, sertlik, creep direnci, çözünürlük direnci, geçirmezlik gibi üfleme döküm için çok ideal bir malzeme olabileceğini düşündüren özelliklere sahiptir7. Malzeme tıpta, kalça eklemleri operasyonlarında ve kalp kapakçı̆̆ı occluder olarak kullanılmaktadır ${ }^{23}$. Asetal- D, zincir dallanmaları olmayan lineer yapıda olup \%75’e varan kristaliteye sahiptir. Bu özelliği nedeniyle sadece mat beyaz renkte bulunmasına rağmen boyanabilirliği sayesinde diş hekimliğinde 14’ü Vita skalası ile uyumlu olmak üzere 20 ayrı renkte kullanılabilmektedir ${ }^{24}$. 


\section{Vectris}

Dolgu maddeli kompozitler diş hekimliğinde uzun zamandır geniş bir kullanım alanına sahipken fiberle desteklenmiş kompozit malzemeler kullanılması yeni bir tekniktir. Vectris, metal desteksiz kuron ve köprü yapımı için geliştirilmiş fiberle güçlendirilmiş bir malzemedir. Translusent olması ve diş rengini taklit edebilmesi estetik özellikleri olarak gösterilmektedir. Ayrıca, revetmana alma, döküm ve döküm sonrası teknik ayrıntılara gerek göstermediğinden çalışma kolaylığı sağlamaktadır. Kompozitle güçlendirilmiş fiber (Fiber-reinforced composite/FRC) tekniğinin fiziksel özellikleri, matriks seçimi, fiber tipi, fiber çapı ve uzunluğu, fiber içeriği (hacim olarak), fiber dağılımı, fiberin ıslatması ve destek maddesinin seçimi ve uygulanışı gibi çeşitli teknik parametrelere bağlıdır²5.

\section{Gereç ve Yöntem}

Farklı sekonder kuron malzemelerinin metal primer kuronlar üzerindeki tutuculuk kayıplarını inceleyen çalışmamız üç etapta gerçekleştirildi.

1. Konus kuronlarda, metal primer kuron üzerinde metal sekonder kuronların o ve o500, 500-1500, 1500-3500 defa takılıp çıkarılması sonucu elde edilen tutunma kuvveti değerlerinin belirlenmesi,

2. Metal primer kuron üzerinde Vectris sekonder kuronların o ve 0-500, 500-1500, 1500-3500 defa takılıp çıkarılması sonucu elde edilen tutunma kuvveti değerlerinin belirlenmesi,

3. Metal primer kuron üzerinde Asetal-D sekonder kuronların o ve 0-500, 500-1500, 1500-3500 defa takılıp çıkarılması sonucu elde edilen tutunma kuvveti değerlerinin belirlenmesi.

Belirlenen dişler üzerinde konus kuronlara uygun şekilde şevli olarak aşındırmalar yapıldı. $2^{\circ}$ lik konverjans açısına sahip örneklerin RTV silikon kalıpları yapıldı. Elde edilen mum maketler fosfat bağlayıcılı revetmana alınarak geleneksel yöntemlerle $\mathrm{Cr}$ $\mathrm{Ni}$ alaşımdan döküldüler. Primer örnekleri $2^{\circ}{ }^{\circ}$ lik konverjans açısına sahip olacak şekilde frezelenip cilalandılar. Her diş için $\mathrm{Cr}-\mathrm{Ni}$ alaşımından 10'ar adet deney modellerinin primerleri elde edildi. 
Elde edilen 40 adet primer örneği üzerine karbonize olabilen akrilikten sekonder kuronlar işlendi, fosfat revetmana alınarak $\mathrm{Cr}-\mathrm{Ni}$ alaşımından dökümleri yapıldı. İç yüzeyleri \%10’luk HF solüsyonunda bekletilerek dış yüzeylerine kumlama yapılarak temizlendiler. Asetal-D sekonder kuronların yapımı için daldırma yöntemi ile mum işlendi. Mum örnekler klasik yöntemlerle muflalama ve mum arıtma işlemi yapıldıktan sonra ürüne ait özel fırında $220^{\circ}$ de 4 bar basınç altında 5 dak. süreyle enjeksiyon işlemi gerçekleştirildi. Muflalar açılıp sekonderlerin yüzeyleri temizlenip tesviyeler yapıldı. Vectris sekonder kuronların elde edilmesi için özel izolasyon maddesiyle primer kuronlar izole edildikten sonra her birine yönerge doğrultusunda özel tabakalar ve şeffaf plaklar yerleştirildi. Örnekler, malzemenin primer örnek üzerine adaptasyonunu sağlayan, ışıkla sertleştirme ve vakum/basınç prensibi ile çalışan özel aygıt içinde tek tek $10 \mathrm{sn}$. süreyle işleme tabi tutuldular.

Deneylerde kullanılan çıkarıp-takma aygıtı 1975 senesinde Caniklioğlu tarafından diş firçalama deneylerinde kullanılmak üzere tasarlanmış olup bu deneylerde kullanılmak üzere kendisi tarafından gözden geçirilerek bazı değişiklikler yapılmıştır. Deney örneklerinin aygıt üzerinde yerleştirilebilmesi ve takıp çıkarma işlemlerinin yapılabilmesi için taşıyıcı parçalar hazırlanmış ve örnekler soğuk akrilik içerisine gömülmek suretiyle bu taşıyıcı parçalara imbus vidalarla sabitlenmiştir.

Deney örneklerinin ilk tutunma kuvvetlerinin ölçülmesinde İstanbul Üniversitesi Mühendislik Fakültesi Kimya Bölümü'nde bulunan çekme aleti kullanıldı. Akrilik blok içine yerleştirilmiş olan örneklerin ilk tutunma kuvveti ölçümleri yapıldı. Özel aygıt ile 500 defa takıp çıkarma işlemi yapıldıktan sonra primer ve sekonder deney örneklerinin sahip oldukları tutunma kuvvetleri tekrar ölçüldü. Aynı ölçümler 1000 ve 2000 defa daha takıp çıkarma işlemi uygulandıktan sonra da tekrarlandı.

Deney örneklerinin o, o-500, 500-1500, 1500-3500 kez takıp çıkartma işlemleri sonrasında elde edilen tutunma kuvveti değerleri istatistiksel olarak gruplar arasında tek yönlü varyans analizi, grup içinde ise Friedman testi ile değerlendirildi. Materyallerin ikili karşılaştırmalarında Student's $t$ testi ve devir sayılarının karşılaştırılmasında ise eşli t testi kullanılmıştır. 


\section{Bulgular}

Deneylerimiz dört ayrı diş grubunda üç ayrı sekonder malzemesinin 0, 0-500, 5001500, 1500-3500 takıp çıartma işlemleri sonrasında elde edilen tutunma kuvveti sonuçlarını içermektedir. Her diş grubuna göre elde dilen ortalama değerleri aşağıdaki tabloda görülmektedir (Tablo 1).

Tablo 1: Her bir sekonder kuron malzemesi için deney sonucu ortalama değerleri

\begin{tabular}{|l|l|l|l|l|}
\hline & $\mathbf{0}$ & $\mathbf{5 0 0}$ & $\mathbf{1 5 0 0}$ & $\mathbf{3 5 0 0}$ \\
\hline Asetal-D & $393,0 \pm 290,2$ & $346,5 \pm 254,6$ & $293,5 \pm 210,6$ & $268,5 \pm 193,5$ \\
\hline Vectris & $398 \pm 333,3$ & $390,8 \pm 321,0$ & $340,7 \pm 277,6$ & $305,4 \pm 262,6$ \\
\hline Metal & $598,5 \pm 175,1$ & $575,7 \pm 173,2$ & $525,0 \pm 162,7$ & $469,0 \pm 145,6$ \\
\hline
\end{tabular}

Asetal-D sekonder kuron malzemesi ile tüm diş gruplarında 0,0-500,500-1500,15003500 takıp çıkarma dönemleri için elde edilen tutunma kuvveti ortalama değerleri aşağıdaki tabloda görülmektedir (Tablo 2).

Tablo 2: Asetal-D ile elde edilen sekonder kuronlarda ortaya çlkan tutunma kuvvetleri ortala değerleri

\begin{tabular}{|l|l|l|l|l|}
\hline ASETAL & $\mathbf{0}$ & $\mathbf{0 - 5 0 0}$ & $\mathbf{5 0 0 - 1 5 0 0}$ & $\mathbf{1 5 0 0 - 3 5 0 0}$ \\
\hline Santral & $223,5 \pm 157,6$ & $186,5 \pm 130,51$ & $153,5 \pm 101,0$ & $135,0 \pm 85,70$ \\
\hline Kanin & $143,0 \pm 58,41$ & $121,0 \pm 48,12$ & $98,5 \pm 37,12$ & $92,5 \pm 35,22$ \\
\hline Premolar & $559,5 \pm 146,71$ & $523,5 \pm 136,95$ & $461,0 \pm 141,85$ & $420,5 \pm 135,74$ \\
\hline Molar & $646,0 \pm 334,47$ & $555,0 \pm 273,39$ & $461,0 \pm 185,14$ & $426,0 \pm 166,81$ \\
\hline
\end{tabular}

Vectris sekonder kuron malzemesi için her diş grubunun 0,0-500,500-1500,1500-3500 takıp çıkartma dönemleri için elde edilen tutunma kuvveti ortalamaları aşağıdaki tabloda görülmektedir (Tablo 3). 
Tablo 3: Vectris ile elde edilen sekonder kuronlarda ortaya çıan tutunma kuvvetlerinin ortalama değerleri

\begin{tabular}{|l|l|l|l|l|}
\hline VECTRIS & O & o-500 & $\mathbf{5 0 0 - 1 5 0 0}$ & $\mathbf{1 5 0 0 - 3 5 0 0}$ \\
\hline Santral & $237,0 \pm 211,08$ & $217,0 \pm 204,22$ & $206,5 \pm 198,48$ & $184,6 \pm 182,01$ \\
\hline Kanin & $188,5 \pm 180,46$ & $167,5 \pm 136,04$ & $160,5 \pm 123,55$ & $140,0 \pm 103,57$ \\
\hline Premolar & $608,0 \pm 432,84$ & $620,0 \pm 400,86$ & $500,0 \pm 346,38$ & $452,0 \pm 345,50$ \\
\hline Molar & $560,0 \pm 247,52$ & $559,0 \pm 216,66$ & $496,0 \pm 214,80$ & $445,0 \pm 208,66$ \\
\hline
\end{tabular}

Metal sekonder kuron malzemesinde her diş grubunun 0,0-500,500-1500,1500-3500 kez takıp çıkartma dönemleri için tutunma kuvveti değerleri ortalamaları aşağıdaki tabloda görülmektedir (Tablo 4).

Tablo 4: Metal ile elde edilen sekonder kuronlarda ortaya çıkan tutunma kuvvetleri ortalama değerleri

\begin{tabular}{|l|l|l|l|l|}
\hline METAL & o & 0-500 & $\mathbf{5 0 0 - 1 5 0 0}$ & $\mathbf{1 5 0 0 - 3 5 0 0}$ \\
\hline Santral & $439,0 \pm 49,99$ & $416,0 \pm 47,19$ & $366,0 \pm 51,47$ & $308,0 \pm 47,09$ \\
\hline Kanin & $486,0 \pm 38,64$ & $465,0 \pm 38,94$ & $426,0 \pm 38,93$ & $396,0 \pm 33,40$ \\
\hline Premolar & $609,0 \pm 70,15$ & $588,0 \pm 65,79$ & $546,0 \pm 55,82$ & $504,0 \pm 52,96$ \\
\hline Molar & $860,0 \pm 74,83$ & $834,0 \pm 75,60$ & $762,0 \pm 74,65$ & $668,0 \pm 75,10$ \\
\hline
\end{tabular}

\section{Tartışma ve Sonuç}

Her üç sekonder kuron malzemesi için tüm diş gruplarında en fazla tutunma kuvveti metal, daha sonra sirasiyla Vectris ve Asetal-D sekonder kuron malzemelerinde elde edilmiştir.

Tüm dişler için ortalama tutunma değerleri ele alındığında, metal-metal arasındaki tutunmanın 3500 kez takıp çıkarma sonucunda dahi gerek Asetal-D gerekse Vectris materyalinin 'o' durumundaki tutuculuğundan daha yüksek olduğu görülmektedir. 
Metal sekonder kuronlarda en iyi tutunma kuvveti değerleri sirasıyla molar, premolar, kanin ve santral diş gruplarına, Vectris sekonder kuronlarda sırasıyla premolar, molar, santral ve kanin gruplarına ve Asetal-D sekonder kuronlarda da sirasiyla molar, premolar, santral ve kanin gruplarına aittir.

Asetal-D’nin her üç devrede de Vectris'e gör daha az tutunma kuvveti sağladığı görülmektedir.

İstatistiksel değerlendirmeler tüm takıp çıkartma dönemlerinde Asetal-D ile Vectris sekonder malzemeleri arasındaki tutunma kuvveti kayıp miktarlarının anlamlı düzeyde farklı olmadığını, sadece metal sekonder kuron malzemesi değerlerinin Asetal-D ve Vectris'e göre anlamlı bir fark taşıdığını göstermektedir.

Takıp çıkartma dönemlerine göre tüm sekonder kuron malzemelerinde her üç evrede de bütün diş gruplarında istatistiksel açıdan anlamlı düzeyde düşüşler olmuştur.

\section{KAYNAKÇA}

1. Dykema RW, Goodacre CJ, Phillps RW. Johnston's Modern Practice in Fixed Prosthodontics. 4. ed. Philadelphia: W.B. Saunders Company; 1986.

2. Caputo AA, Stanlee JP. Biomechanics in Clinical Dentistry. Chicago: Quintessence Publishing Co; 1987.

3. Berman H. Primary substructures and removable partial dentures: A literature review. J Prosthet Dent. 1960;10:724-732.

4. Morrow R, Feldmann EE, Rudd KD. Tooth-supported complete dentures: An approach to preventive prosthodontics. J Prosthet Dent. 1969;21(5):513-522.

5. Körber KH. Konuskronen Teleskope, Einführung in Klinik und Technik. Heidelberg: Dr. Alfred Hüthig Verlag GmbH; 1973.

6. Körber KH. Zahnartzliche Protetik. 3. baskı. Stuttgart: Georg Thieme Verlag; 1985 .

7. Crum RT, Loiselle RT. Oral perception and proprioception: A review of the literature and its significance to prosthodontics. J Prosthet Dent. 1972;29(2):215-230.

8. Crum RJ, Rooney GE. Alveolar bone loss in overdentures: A 5 year study. $J$ Prosthet Dent. 1978;40(6):610-613. 
9. Igarashi Y, Goto T. Ten year follow-up study of conical crown retained dentures. Int Journ of Prosth. 1996;10(2):149-155.

10. Berman H. Primary substructures and removable partial dentures: A literature review. J Prosthet Dent. 1960;10:724-732.

11. Langer A. Telescope retainers for removable partial dentures. $J$ Prosthet Dent. 1981;45(1):37-43.

12. Ogata K, Okunishi M, Miyake T. Longitudinal study on forces transmitted from denture base retainers of lower distal-extension removable partial dentures with conus crown telescopic system. Journ Oral Rehab. 1993;20:69-77.

13. Lenz J. Ein mathematiches modell zur berechnung des haft-und festigsverhaltens von konischen telekopkronen. Dtsch Zahnartzl.1982;37:7-15.

14. Langer A. Telescope retainers in prosthodontic restorations. Isr J Dent Med. 1973;22:107.

15. Körber KH. Konuskronen phsyshalich definiertes teleskopsystem. Dtsch Zahnartz Z. 1968;23:619.

16. Ohkawa S, Okane K, Nagasawa T, Tsuru H. Changes in retention of various telescope crown assemblies over long-term use. $J$ Prosthet Dent. 1990;64(2):153-158.

17. Lenz J, Pelka H, Schindler HJ. Nichtdelmetalle in der Konuskronen-Technik. Phillip Journal. 1986;5:221-225.

18. Lenz P, Gilde H, Süssman K. VMK-Konuskronen im Dauerverschleissversuch. Dtsch Zahnartzl.1978;33:453-455.

19. Morris HF. A new assessment system for noting metal ceramic crown. $J$ Prosthet Dent. 1986;56(5):546-551.

20. Komatsu T. Effects of surface treatments of superdrawn polyoxymethylene fibers on adhesion to epoxy resins. J Appl Poly Scien. 1996;59:1137-1143.

21. Masomoto J, Iwaisako T, Matsuzaki K. Development of an advanced process for manufacturing polyacetal resin. Pure Appl Chem. 1992;29(6):441-456.

22. Beguelin $\mathrm{PH}$, Kausch $\mathrm{HH}$. The effect of the loading rate on the fracture thoughness of poly (methyl metacrylate), polyacetal, polyetheretherketone and modified PVC. Journ of Mat Scien. 1994;29:91-98.

23. Corigliano M, Romano F, Mirra M, Fazio PD. Riabilitazione protesica e gnatologia cilinica. Vi Congresso di Dicipline Odontostomatologiche. 1994. 
24. Pressing. Asetal Dental tanıtım broşürü

25. Altieri J, Burstone C, Goldberg J. Longitudinal clinical evaluation of fiber reinforced composite fixed partial dentures: Apilo study. J Prosthet Dent. 1994;71(1):16-22. 